\title{
Identificação de nematoides parasitos de plantas em bulbos ornamentais e uso da hidrotermoterapia no controle de Pratylenchus crenatus em lírio ${ }^{(1)}$
}

\author{
SAMARA AZEVEDO DE OLIVEIRA (2); JULIANA EULÁLIO (3); \\ ISABELA CRISTINA CARETA BAROZZI (2); FABIANA CUNHA GIORA (2); \\ ROBERTO KAZUHIRO KUBO ${ }^{(4)}$; CLÁUDIO MARCELO GONÇALVES DE OLIVEIRA ${ }^{(4)}$
}

\begin{abstract}
RESUMO
Os nematoides associados às ornamentais bulbosas podem afetar todas as partes da planta, parasitando, além das raízes e bulbos, também a parte aérea. O objetivo do presente trabalho foi diagnosticar as espécies de nematoides encontrados associados às principais espécies de bulbos ornamentais cultivados no Brasil ou importados da Holanda e Estados Unidos. Os resultados desse levantamento indicam que as amostras de bulbos provenientes da Holanda e Estados Unidos, analisadas no laboratório de nematologia do Instituto Biológico, em sua maioria, não apresentaram nematoides fitoparasitos, apenas nematoides de vida livre (60\% das 332 amostras analisadas). Entretanto, em 35\% das amostras, foram encontrados nematoides do gênero Pratylenchus (P. penetrans e P. crenatus) e em 5\%, Meloidogyne (M. incognita e M. javanica). Com relação às amostras coletadas no Brasil, em $30 \%$ delas foram detectados nematoides do gênero Pratylenchus, tendo sido identificada a presença de $P$. zeae em amostras de Ornithogalum sp. e Tulbaghia sp., provenientes de Holambra - SP, e Lilium cv. Stargaze, proveniente de Munhoz - MG. Trata-se do primeiro relato dessa espécie em ornamentais bulbosas no país. Nematoides do gênero Meloidogyne ocorreram somente em $10 \%$ das amostras analisadas, e entre esses nematoides foi identificada pela primeira vez no Brasil a espécie M. incognita em bulbos de Colocasia sp. e Polianthes tuberosa, provenientes de Holambra - SP. No entanto, não se conhece a extensão dos danos causados pelos nematoides das galhas, sendo necessários futuros estudos de patogenicidade. Ademais, avaliou-se a eficiência do método de hidrotermoterapia no controle de Pratylenchus crenatus presente em raízes e bulbos de lírios provenientes da Holanda. Foram testadas variações de tempo e temperatura, sendo que a mais eficiente foi o banho térmico a $39^{\circ} \mathrm{C}$ por duas horas, que se mostrou eficaz no controle dos nematoides e não afetou o desenvolvimento das plantas.
\end{abstract}

Palavras-chave: Pratylenchus crenatus, P. zeae, Meloidogyne incognita, M. javanica, hidrotermoterapia.

\author{
ABSTRACT \\ Identification of plant-parasitic nematodes of ornamental bulbs and use of \\ hidrotermotherapy to control Pratylenchus crenatus on lily
}

\begin{abstract}
Nematodes associated to ornamental bulbs can affect all parts of the plants, including roots, bulbs, and also the shoot part (leaves). The objective of the present work was to discuss the importance of nematode species found associated to the most cultivated species of ornamental bulbs in Brazil and those imported from Netherlands and the United States. Results indicated that the majority of the ornamental plants imported from Netherlands and the United States showed only free living nematodes (60\% of 332 samples). However, in 35\% of the samples were found Pratylenchus (P. penetrans and $P$. crenatus), and in 5\%, Meloidogyne (M. incognita and M. javanica). In relation to the samples collected in Brazil, in $30 \%$ were detected Pratylenchus, including P. zeae in Ornithogalum sp. and Tulbaghia sp., from Holambra-SP and Lilium cv. Stargaze, from Munhoz-MG, which constitute in the first report of this species in ornamental bulbs in Brazil. Meloidogyne was found in $10 \%$ of the samples analyzed. Meloidogyne incognita was reported for the first time in Brazil in Colocasia sp. and Polianthes tuberosa from Holambra-SP. However, it is not known if the presence of these nematodes can affect the production and the quality of the ornamental bulbs, thus future studies are required to clarify this possibility. Additionally, it was tested the efficiency of the method of hidrotermotherapy in the control of Pratylenchus crenatus present in lily hybrid Jet Set imported from Netherlands. The most efficient variation of time and temperature assessed was the thermal bath at $39^{\circ} \mathrm{C}$ per two hours, which showed to be efficient in the control of nematodes without affect the plants development.
\end{abstract}

Keywords: Pratylenchus crenatus, P. zeae, Meloidogyne incognita, M. javanica, hidrotermotherapy.

\section{INTRODUÇÃO}

A floricultura abrange o cultivo de flores e plantas ornamentais, desde as culturas de flores para corte até a produção de mudas arbóreas de porte elevado (CASTRO, 1998). No Brasil, o mercado de flores e plantas ornamentais encontra-se em expansão, movimentando em torno de 800 milhões de dólares/ano, estimulando produtores a investir nessa área (JUNQUEIRA e PEETZ, 2002).

A Holanda e os Estados Unidos são os parceiros comerciais mais importantes da floricultura brasileira, respondendo por $78,4 \%$ do valor das exportações do setor. A Holanda é o principal destino em termos de valor comercializado (US\$20,2 milhões), respondendo por $57,3 \%$ do total. Os Estados Unidos ocupam o segundo lugar, com US\$7,4 milhões. Outros países que importam

\footnotetext{
(1) Recebido em 24/10/2011 e aceito para publicação em 13/06/2012.

(2) Acadêmica de Ciências Biológicas da PUC-Campinas, Bolsista PIBIC IB-CNPq.

(3) Acadêmica de Ciências Biológicas da PUC-Campinas, Bolsista do Consórcio Pesquisa Café.

(4) Pesquisador Científico, Laboratório de Nematologia, Instituto Biológico, Caixa Postal 70, 13001-970, Campinas, SP, Brasil.
} 
produtos da floricultura brasileira são Itália $(7,0 \%)$, Japão (2,3\%) e Bélgica (2,1\%) (KIYUNA et al., 2008).

As espécies de bulbosas ornamentais, como lírio (Lilium sp), amarílis (Hippeastrum sp), gladíolo (Gladiolus $\mathrm{sp}$ ), alstroemeria (Alstroemeria $\mathrm{sp}$ ) e calla (Zantedeschia $\mathrm{sp}$ ), são vegetativamente propagadas para fins comerciais. Esta forma de multiplicação das espécies de interesse econômico propicia a disseminação, de forma muito eficaz e em grande escala, de doenças causadas por vírus e nematoides. Desta forma, torna-se estratégico detectar e identificar os patógenos em bulbos importados bem como fazer levantamentos dos nematoides já estabelecidos em cultivos comerciais.

Os nematoides associados às plantas ornamentais parasitam principalmente os órgãos subterrâneos (raízes, rizomas, tubérculos e bulbos), mas também a parte aérea (caules e folhas). As perdas causadas são de dois tipos: redução da produção e depreciação da qualidade do produto a ser comercializado.

No Brasil, mais de 20 gêneros de fitonematoides foram detectados em associação a plantas ornamentais (OLIVEIRA, 2006; OLIVEIRA e KUBO, 2006; OLIVEIRA et al., 2007; OLIVEIRA, 2008). De forma geral, os gêneros Meloidogyne, Pratylenchus, Radopholus e Aphelenchoides são considerados os principais no Brasil pela frequência com que ocorrem e intensidade das perdas causadas (OLIVEIRA et al., 2007). Porém, o conhecimento disponível na literatura sobre a ocorrência e medidas de controle de nematoides em plantas ornamentais bulbosas é ainda limitado.

Dessa forma, esse trabalho foi elaborado com o objetivo principal de identificar as principais espécies de nematoides parasitas de plantas ornamentais bulbosas. Ademais, avaliou-se a eficiência do método de hidrotermoterapia no controle do nematoide $P$. crenatus presente em raízes dos bulbos de lírios importados da Holanda.

\section{MATERIAL E MÉTODOS}

\subsection{Identificação}

As 24 amostras nacionais para as análises nematológicas foram coletadas nas principais áreas produtoras de ornamentais bulbosas dos seguintes municípios: 14 amostras de Hyppeastrum sp (Paraipaba, Ceará); Colocasia sp, Zephyrantes sp, Polianthes tuberosa, Ornithogalum sp, Tulbaghia sp e Crinum powelli (Holambra, São Paulo); e quatro amostras de Lilium sp (Munhoz, Minas Gerais). Cada subamostra foi composta por uma planta inteira (raízes, bulbos e folhas) e $1 \mathrm{~kg}$ de solo/substrato. Cada amostra foi composta de pelo menos quatro subamostras.

Ademais, foram registradas 288 amostras de lírios, sete amostras de Zantedeschia sp, quatro de Hyacinthus orientalis, uma de Narcissus tazetta, seis de Tulipa gesneriana, cinco de Gladiolus $x$ Hortulanus e uma amostra de Hippeastrum sp., importadas da Holanda, e dezessete amostras de Caladium x Hortulanum, provenientes dos Estados Unidos, encaminhadas pelo Ministério da Agricultura, Abastecimento e Pecuária (Mapa), para análise nematológica, à clínica mantida pelo Laboratório de Nematologia do Centro Experimental Central do Instituto Biológico (CEIB/Instituto Biológico), em Campinas, SP, no período de 2010 a 2011.

Os nematoides presentes no substrato e nas partes vegetais foram extraídos pelos métodos de JENKINS (1964) e COOLEN e D'HERDE (1972), respectivamente, sendo os espécimes obtidos mortos pelo calor, por aquecimento em banho-maria a $60^{\circ} \mathrm{C}$, fixados e conservados em formalina $2 \%$. A estimativa populacional de cada gênero foi obtida pela contagem em lâminas de Peters, utilizando microscópio de luz. Foram feitas duas contagens, obtendose o número dos espécimes em $1 \mathrm{ml}$ da amostra total. Para a obtenção da estimativa populacional total em cada gênero, os valores médios obtidos por $\mathrm{ml}$ foram multiplicados pelo volume total da amostra.

Para a identificação das espécies, recorreu-se a lâminas temporárias (formalina) e/ou permanentes (glicerina), examinadas em microscópio. A identificação foi feita principalmente pelo exame dessas lâminas, baseada em características morfológicas e morfométricas, e pela utilização de chaves taxonômicas específicas para cada gênero encontrado.

A identificação da espécie de Meloidogyne foi feita pelo exame da configuração perineal e confirmada pela técnica de eletroforese de isoenzima, pela análise dos fenótipos de esterase (CARNEIRO e ALMEIDA, 2001).

\subsection{Hidrotermoterapia}

Estudou-se a eficiência do uso de hidrotermoterapia (tratamento com água aquecida) comparada ao tratamento com nematicidas no controle de nematóides presentes em raízes e bulbos de lírio (Lilium sp), Híbrido Oriental JetSet. $\mathrm{O}$ experimento foi conduzido em casa de vegetação, no município de Holambra, SP.

Adotou-se o delineamento experimental inteiramente ao acaso, com 7 tratamentos e 4 repetições (Tabela 1). Cada parcela foi constituída de 200 bulbos de lírio oriental para cultivo em vaso. Os bulbos foram importados da Holanda e estavam, naturalmente, infestados por nematoides.

Para o tratamento hidrotérmico dos bulbos de lírio, utilizou-se um equipamento com controle de temperatura, Figura 1, constituído por uma caixa plástica com capacidade de $1000 \mathrm{~L}$, equipado com resistência trifásica. A temperatura foi controlada, utilizando um termostato conectado a um sensor e interligado a computador para monitoramento das variações de temperatura.

Assim, isoladamente, cada parcela composta de 200 bulbos de lírio oriental foi imersa nesse sistema de banhomaria, de acordo com o delineamento experimental proposto (Tabela 1).

Para os tratamentos com os nematicidas Carbofuran e Abamectina, 800 bulbos foram imersos durante 15 minutos na calda do nematicida, de acordo com o delineamento experimental proposto (Tabela 1).

Foram estimadas as densidades populacionais dos nematoides presentes nas raízes e nos bulbos de lírio (10 g/parcela) 60 dias após os tratamentos. Os nematoides presentes nas raízes e bulbos foram extraídos pelo método de COOLEN e D'HERDE (1972), sendo os espécimes obtidos mortos por aquecimento em banho-maria a $60^{\circ} \mathrm{C}$, fixados e conservados em formalina $2 \%$. A estimativa populacional dos nematoides foi obtida pela contagem em lâminas de Peters, utilizando microscópio óptico. Foram 
feitas duas contagens, obtendo-se o número dos espécimes em $1 \mathrm{ml}$ da amostra total. Para a obtenção da estimativa populacional total em cada gênero, os valores médios por $\mathrm{ml}$ foram multiplicados pelo volume total da amostra.

Além disso, foi verificada mensalmente a influência dos tratamentos na germinação e desenvolvimento das plantas cultivadas em vaso, em casa de vegetação.

Para a identificação da espécie, foram montadas lâminas temporárias em formalina, examinadas em microscópio. A identificação foi feita principalmente pelo exame dessas lâminas, baseada em características morfológicas e morfométricas. Além disso, foi utilizada a tecnologia do código de barras do DNA, conforme relatado por Oliveira et al. (2009).

\section{RESULTADOS E DISCUSSÃO}

\subsection{Identificação}

Das 332 amostras analisadas, importadas da Holanda e Estados Unidos, cerca de $60 \%$ não estavam infectadas por nematoides fitoparasitos, sendo encontrados somente nematoides de vida livre. Em 35\% das amostras foram encontrados nematoides fitoparasitos do gênero Pratylenchus, sendo que $P$. penetrans foi a espécie de maior incidência nas amostras de lírio, correspondendo a 33\% do total das amostras, enquanto P. crenatus foi encontrado em $2 \%$ do total de amostras, presente em raízes de lírios Híbrido Oriental Early Yellow, Muscadet, True Emotion, Cobra e JetSet. Além disso, 5\% das amostras estavam infectadas com Meloidogyne incognita e M. javanica, encontrados, respectivamente, em amostras de Caladium x Hortulanum, provenientes dos Estados Unidos, e Zantedeschia sp, da Holanda (Figura 2).

De acordo com a Figura 3, nas 24 amostras coletadas no território nacional, o nematoide fitoparasita mais frequente em bulbos de ornamentais também foi do gênero Pratylenchus. Nas amostras de Ornithogalum sp e Tulbaghia sp, provenientes de Holambra, SP, e Lilium cv. Stargaze, proveniente de Munhoz, MG, identificouse $P$. zeae. Trata-se do primeiro relato dessa espécie em ornamentais bulbosas no Brasil, mas ainda não se conhece a extensão dos danos causados por esse nematoide.

Da mesma forma, com relação às amostras de Colocasia sp e Polianthes tuberosa, através da análise dos fenótipos de esterase, Figura 4, e do padrão da região perineal das fêmeas, foram detectados pela primeira vez espécimes de $M$. incognita, mas também não se conhece se a presença desse nematoide pode afetar a produção e qualidade das plantas, sendo necessários futuros estudos de patogenicidade. Não foram detectados nematoides parasitos de plantas nas seguintes ornamentais: Hyacinthus orientalis, Narcissus tazetta, Tulipa gesneriana, Gladiolus $x$ Hortulanus e Hippeastrum sp.

Recentemente, OLIVEIRA et al. (2000), durante levantamento de nematoides em plantas ornamentais cultivadas nos estados de São Paulo e Minas Gerais, reportaram nova ocorrência de $P$. brachyurus em diversos cultivares de lírios. Os nematoides do gênero Pratylenchus são considerados um dos grupos de fitoparasitos de elevada relevância em ornamentais bulbosas, graças à sua frequência e aos danos causados às plantas, o que resulta na redução da produção e desvalorização do produto pela sua baixa qualidade (OLIVEIRA et al., 2007). Por exemplo, $P$. penetrans é bastante conhecido pelos danos causados em lírios e em diversos outros tipos de plantas. Os principais sintomas são: baixo desenvolvimento da parte aérea da planta e crescimento limitado das raízes, muitas vezes com presença de lesões (WESTERDAHL et al., 1998).

Cabe ressaltar que bulbos de lírios e outras ornamentais podem disseminar nematoides, constituindo fator limitante para sua comercialização pelas restrições nas legislações fitossanitárias (OLIVEIRA et al., 2009). No presente estudo, detectou-se $P$. crenatus em raízes de lírio importado da Holanda. Trata-se de nematoide quarentenário, considerado praga ausente no Brasil. Essa espécie se encontra amplamente distribuída em diversos países europeus. Na Holanda, por exemplo, já foi detectada em cultivos de batata (CASTILLO e VOVLAS, 2007). Nos Estados Unidos, também ocorre parasitando batata nos estados de Maine, New York e Ohio (CASTILLO e VOVLAS, 2007). Além disso, há relato de que $P$. crenatus ocorre na Califórnia associado a lírio (Lilium longiflorum var. eximium) (NORTON et al., 1984). Devido a esses relatos, é cada vez mais evidente a importância de serem testados novos métodos de controle de nematoides fitoparasitos. Dessa forma, planejou-se o experimento com hidrotermoterapia, no presente trabalho, visando a avaliar a eficiência de uma medida de controle pelo uso da água aquecida no tratamento de bulbos de lírios infectados pelo nematoide $P$. crenatus.

\subsection{Hidrotermoterapia \\ Influência dos tratamentos na germinação e desenvolvimento das plantas de lírio}

Um mês após o plantio, foi verificada a influência dos tratamentos na germinação dos bulbos e desenvolvimento das plantas de lírio. Observou-se que o tratamento hidrotérmico com temperatura a $39{ }^{\circ} \mathrm{C}$ por 2 horas, Tratamento 2, não afetou a germinação dos bulbos de lírio (Figura 5A). Percentualmente, esse tratamento foi igual à testemunha, com $85 \%$ de germinação dos bulbos. Quando se adicionou formalina a $0,3 \%$, Tratamento 3 , algumas plantas apresentaram sintomas de fitotoxidez (Figura 5C). Por outro lado, o tratamento hidrotérmico com temperatura mais elevada (42ㄷ por 2 horas - Tratamento 5) afetou significativamente a germinação e o desenvolvimento inicial das plantas, Tabela 2 e Figura 5B, inviabilizando sobremaneira sua utilização. Cabe ressaltar que ambos os tratamentos, Tratamentos 6 e 7, com produtos nematicidas, não provocaram fitotoxidez às plantas de lírio, Figura 5D, tampouco afetaram a germinação dos bulbos. Respectivamente, a porcentagem de germinação para os tratamentos com Carbofuran e Abamectina foi de 94 e 91\% (Tabela 2).

\section{Densidade populacional de nematoides extraídos das raízes de lírio}

A identificação de $P$. crenatus foi confirmada pelo sequenciamento da expansão D2/D3 do $28 \mathrm{~S}$ rDNA. As sequências obtidas foram comparadas às sequências de outras espécies de nematoides depositadas no banco de dados (GenBank, http://www.ncbi.nlm.nih.gov) para a 
identificação de homologia. Com base nessa comparação, concluiu-se que o nematoide presente nas raízes de lírio cv. JetSet tratava-se de $P$. crenatus, uma vez que apresentou alto grau de homologia com uma população dessa espécie (código de acesso U47549.1).

Com relação ao número de $P$. crenatus nas raízes, Figura 6, observou-se diferença estatística entre a testemunha (37,5 nematoides por $10 \mathrm{~g}$ de raízes) e todos os demais tratamentos com hidrotermoterapia ou nematicidas (praticamente nenhum nematoide foi detectado nas raízes), evidenciando a eficiência no controle desse nematoide. Nenhum espécime de Pratylenchus foi extraído dos bulbos de lírio, inclusive na testemunha, evidenciando que o sítio de parasitismo desse nematoide se limita às raízes de lírio. De forma semelhante, KUBO e OLIVEIRA (2009) constataram que o número de $P$. penetrans na região do prato basal e das escamas internas e externas em bulbos de amarílis foi nulo. No entanto, nas raízes foram quantificados em média 69 espécimes, juvenis e adultos, de $P$. penetrans por grama de raiz. Com base nos resultados obtidos, podese concluir que o sítio preferencial de parasitismo de $P$. penetrans se restringe às raízes de amarílis. Portanto, a análise nematológica das raízes de ornamentais bulbosas é imprescindível na detecção desses nematoides.

$\mathrm{O}$ uso da hidrotermoterapia mostrou-se eficiente no controle de P. crenatus presente em diferentes lotes de bulbos de lírios cv. JetSet importados da Holanda, nas temperaturas testadas. Este método alternativo de controle de nematoides fitoparasitos já foi testado em diversas culturas infectadas por diferentes espécies de nematoides (FORTUNER e WILLIAMS, 1975), obtendo sucesso na maioria dos casos, controlando os nematoides sem prejudicar o desenvolvimento das plantas.

O tratamento hidrotérmico com temperatura a $39^{\circ} \mathrm{C}$ por 2 horas, Tratamento 2, não afetou a germinação dos bulbos de lírio e foi eficaz no controle de $P$. crenatus,. Por outro lado, o tratamento hidrotérmico com temperatura mais elevada $\left(42^{\circ} \mathrm{C}\right.$ por 2 horas - Tratamento 5) também foi eficiente no controle dos nematoides, porém, afetou significativamente a germinação dos bulbos e o desenvolvimento inicial das plantas, o que torna sua utilização inviável. Cabe ressaltar que, ao final do período experimental, todas as parcelas foram destruídas, inclusive o substrato, pelo tratamento por vapor $\left(120^{\circ} \mathrm{C}\right)$, evitando-se, dessa forma, a disseminação dos nematoides. Além disso, a ocorrência de $P$. crenatus em bulbos de lírio foi comunicada ao Ministério da Agricultura, Pecuária e Abastecimento.

\section{CONCLUSÕES}

Através do presente trabalho, identificou-se pela primeira vez no Brasil, associadas à ornamentais bulbosas, as espécies $M$. incognita em bulbos de Colocasia sp e Polianthes tuberosa (Holambra - SP.) e P. zeae em Ornithogalum sp e Tulbaghia sp (Holambra-SP.) e Lilium cv. Stargaze (Munhoz - MG). No entanto, não se conhece a extensão dos danos causados por esses nematoides, sendo necessários futuros estudos de patogenicidade. Em relação às amostras importadas da Holanda e EUA, foi detectada maior frequência de $P$. penetrans, confirmando que materiais vegetais importados destinados ao plantio podem introduzir e disseminar nematoides fitoparasitos no país.

A técnica de hidrotermoterapia se mostrou eficiente e viável no controle de nematoides fitoparasitos de raízes de bulbo de lírios, desde que seja utilizada a $39^{\circ} \mathrm{C}$ por $2 \mathrm{~h}$, para que não haja danos ao desenvolvimento das plantas.

\section{REFERÊNCIAS}

CARNEIRO, R.M.D.G.; M.R.A. ALMEIDA. Técnica de eletroforese usada no estudo de enzimas dos nematoides de galhas para identificação de espécies. Nematologia Brasileira, Piracicaba, v.25, n.1, p.35-44. 2001.

CASTILlO, P.; VOVLAS, N. Pratylenchus (Nematoda: Pratylenchidae): Diagnosis, Biology, Pathogenicity and Management, Leiden: Brill, 2007. 530p.

CASTRO, C. E. F. Cadeia produtiva de flores e plantas ornamentais. Revista Brasileira de Horticultura Ornamental, Campinas, v.4, n.1/2, p.1-46, 1998.

COOLEN, W. A.; D'HERDE, C. J. A method for the quantitative extraction of nematodes from plant tissue. State Nematology and Entomology Research Station, Belgium, p.77, 1972.

FORTUNER, R.; WILLIAMS, K. J. O. Review of the literature on Aphelenchoides besseyi Christie, 1942, the nematode causing "white tip" disease in rice. Helminthological Abstracts, Series B. Plant Nematology, Herts, v.44., p.1-40, 1975.

JENKINS, W. R. A rapid centrifugal flotation technique for separating nematodes from soil. Plant Disease Reporter, Washington, v.48, n.9, p.692, 1964.

JUNQUEIRA, A. H.; PEETZ, M. S. Os polos de produção de flores e plantas ornamentais do Brasil: uma análise do potencial exportador. Revista Brasileira de Horticultura Ornamental, Campinas, v.8, n.1-2, p.25-47, 2002.

KIYUNA, I., ÂNGELO; J.A., COELHO, P.J. FloriculturA - DESEMPENHO do COMÉrcio EXterior em 2007. ANÁlises e Indicadores do Agronegócio. v.3. Net. São Paulo. 2008. Disponível em http://www.iea.sp.gov.br/out/verTexto. php?codTexto=9186. Acesso em: 17 nov. 2008 .

KUBO, R. K.; OLIVEIRA, C. M. G. Sítio de parasitismo de Pratylenchus penetrans em bulbos de amarílis (Hippeastrum x hybridum). In: REUNIÃO ANUAL DO INSTITUTO BIOLÓGICO, 22, São Paulo, 2009. Anais... São Paulo, Instituto Biológico, 2009. p.71.

NORTON, D. C. et al. Distribution of plant-parasitic nematode species in North America. Society of Nematologists. Universidade de Wisconsin, Madison, p. 205, 1984.

OLIVEIRA, C. M. G. Nematoides Parasitos de Plantas Ornamentais no Brasil. Fitopatologia Brasileira, Lavras, v.31, p.S117-S118, 2006 
OLIVEIRA, C. M. G. Nematoides parasitos de plantas ornamentais: Pragas e doenças, Alexandre, M. A. V.; Duarte, L. M. L.; Campos-Farinha, A. E. C. (Eds). Instituto Biológico, São Paulo. p. 189-206, 2008.

OLIVEIRA, C. M. G., KUBO, R. K. Novos assinalamentos de nematoides de parte aérea (Aphelenchoides spp.) em plantas de begônia no Brasil. Revista Brasileira de Horticultura Ornamental, Campinas, v.12, p.134-137, 2006.

OLIVEIRA, C. M. G. et al. Diagnose de Aphelenchoides fragariae e Pratylenchus spp. pela aplicação da tecnologia do código de barras do DNA. Nematologia Brasileira, Piracicaba, v.33 p.218-225, 2009.

OLIVEIRA, C. M. G. et al. Ocorrência de nematoides fitoparasitos em plantas ornamentais nos Estados de São Paulo e Minas Gerais. Revista Brasileira de Horticultura Ornamental, Campinas, v.13, p.135-141, 2007.

WESTERDAHL, B. B. et al. Problems associated with crop rotation for management of Pratylenchus penetrans on easter lily. Journal of Nematology, Lawrence, v. 30, p. 581-589, 1998.

Tabela 1. Tratamentos utilizados no controle de Pratylenchus crenatus em raízes e bulbos de lírio Table 1. Treatments used to control Pratylenchus crenatus on roots and bulbs of lily

\begin{tabular}{|c|c|}
\hline Tratamentos & Temperatura/tempo \\
\hline 1. Testemunha & - \\
\hline 2. tratamento hidrotérmico & $39^{\circ} \mathrm{C}$ por 2 horas \\
\hline 3. tratamento hidrotérmico + formalina $0,3 \%$ & $39^{\circ} \mathrm{C}$ por 2 horas \\
\hline 4. tratamento com formalina $1 \%$ & temperatura ambiente \\
\hline 5. tratamento hidrotérmico & $42^{\circ} \mathrm{C}$ por 2 horas \\
\hline 6. tratamento com nematicida Carbofuram 350 SC & $\begin{array}{l}\text { Dose } 400 \mathrm{ml} \text { PC/100L de água } \\
\text { (imersão dos bulbos, durante } 15 \\
\text { minutos na calda do nematicida) }\end{array}$ \\
\hline $\begin{array}{l}\text { 7. tratamento com nematicida Abamectina (Avicta } 500 \\
\text { FS) }\end{array}$ & $\begin{array}{c}10 \mathrm{ml} \text { de AVICTA / L de água } \\
\text { (AVICTA: } 500 \mathrm{~g} \text { de } \\
\text { abamectina/L) }\end{array}$ \\
\hline & $\begin{array}{l}\text { imersão dos bulbos por } 15 \text { min } \\
\text { em solução nematicida }\end{array}$ \\
\hline
\end{tabular}


Tabela 2. Influência dos tratamentos na germinação de bulbos e desenvolvimento das plantas de lírio, 30 dias após os tratamentos e sintomas de lesão foliar (60 dias após os tratamentos). Valores médios de 4 repetições

Table 2. Influence of treatments on stand and development of lily plants, 30 days after bulbs treatment. Average of 4 replicates

\begin{tabular}{|c|c|c|c|c|}
\hline \multirow[t]{2}{*}{ Tratamentos } & \multicolumn{2}{|c|}{ № final de plantas } & \multicolumn{2}{|c|}{$\begin{array}{c}\text { Plantas com } \\
\text { desenvolvimento } \\
\text { insatisfatório }\end{array}$} \\
\hline & média & $\begin{array}{c}\% \text { de } \\
\text { germinação }\end{array}$ & média & $\%$ \\
\hline 1. Testemunha & 169 & 85 & 4 & 2 \\
\hline \multicolumn{5}{|l|}{ 2. hidrotérmico } \\
\hline$\left(39^{\circ} \mathrm{C} / 2 \mathrm{~h}\right)$ & 169 & 85 & 8 & 4 \\
\hline \multicolumn{5}{|l|}{$\begin{array}{l}\text { 3. hidrotérmico + } \\
\text { formalina } 0,3 \%\end{array}$} \\
\hline$\left(39^{\circ} \mathrm{C} / 2 \mathrm{~h}\right)$ & 115 & 58 & 28 & 24 \\
\hline formalina $1 \%\left(\mathrm{~T}^{\circ} \mathrm{C}\right.$ & \multicolumn{4}{|c|}{ 4. tratamento com } \\
\hline ambiente) & 186 & 93 & 5 & 2 \\
\hline \multicolumn{5}{|l|}{ 5. tratamento } \\
\hline \multicolumn{5}{|l|}{ hidrotérmico } \\
\hline$\left(42^{\circ} \mathrm{C} / 2 \mathrm{~h}\right)$ & 0 & 0 & - & - \\
\hline \multicolumn{5}{|c|}{ 6. Carbofuram 350} \\
\hline SC (Furadan) & 188 & 94 & 4 & 2 \\
\hline \multicolumn{5}{|l|}{ 7. Abamectina } \\
\hline (Avicta 500 FS) & 181 & 91 & 4 & 2 \\
\hline
\end{tabular}

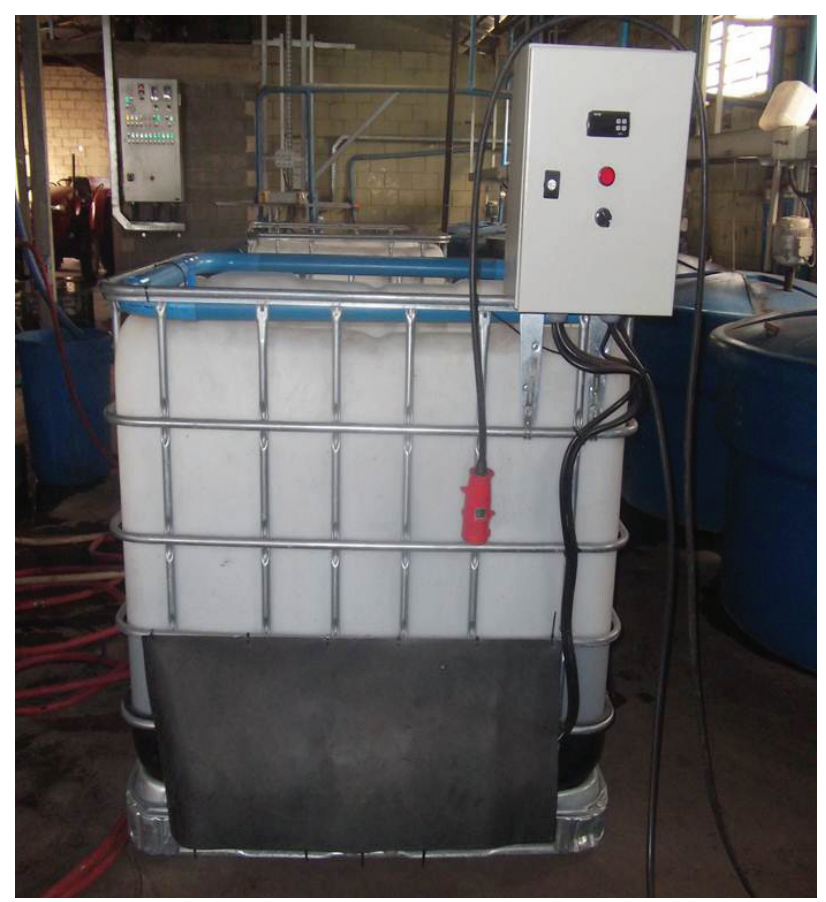

Figura 1. Protótipo utilizado como banho-maria para o tratamento dos bulbos de lírio. Figure 1. Prototype used for hot water treatment in lily bulbs. 


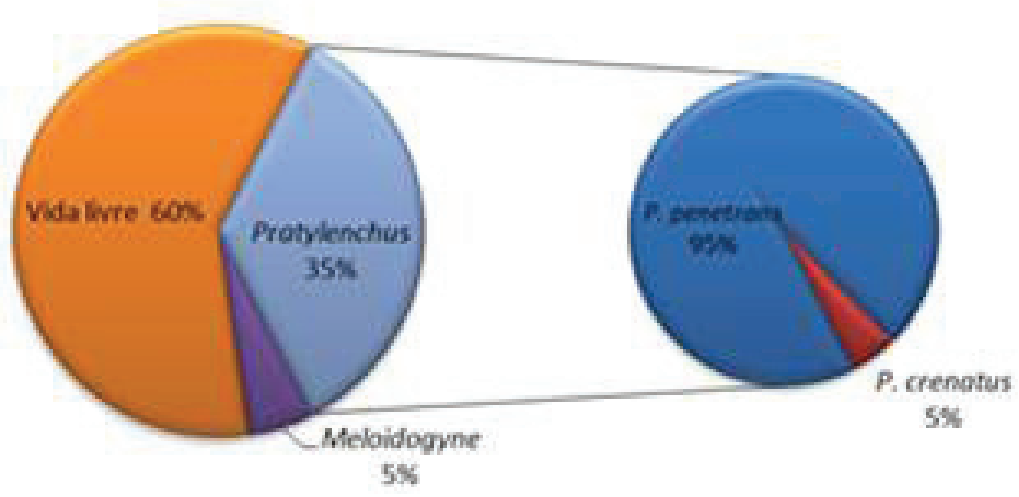

Figura 2. Porcentagem de nematoides identificados em bulbos de ornamentais importados da Holanda e EUA.

Figure 2. Percentage of nematodes identified in imported ornamental bulbs from Netherlands and USA.
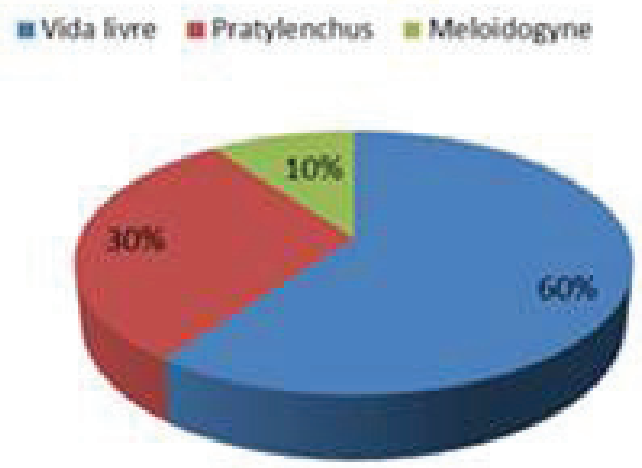

Figura 3. Nematoides identificados em amostras de plantas ornamentais bulbosas coletadas nos Estados do Ceará (Paraipaba), São Paulo (Holambra) e Minas Gerais (Munhoz).

Figure 3. Nematodes identified in Brazilian samples.

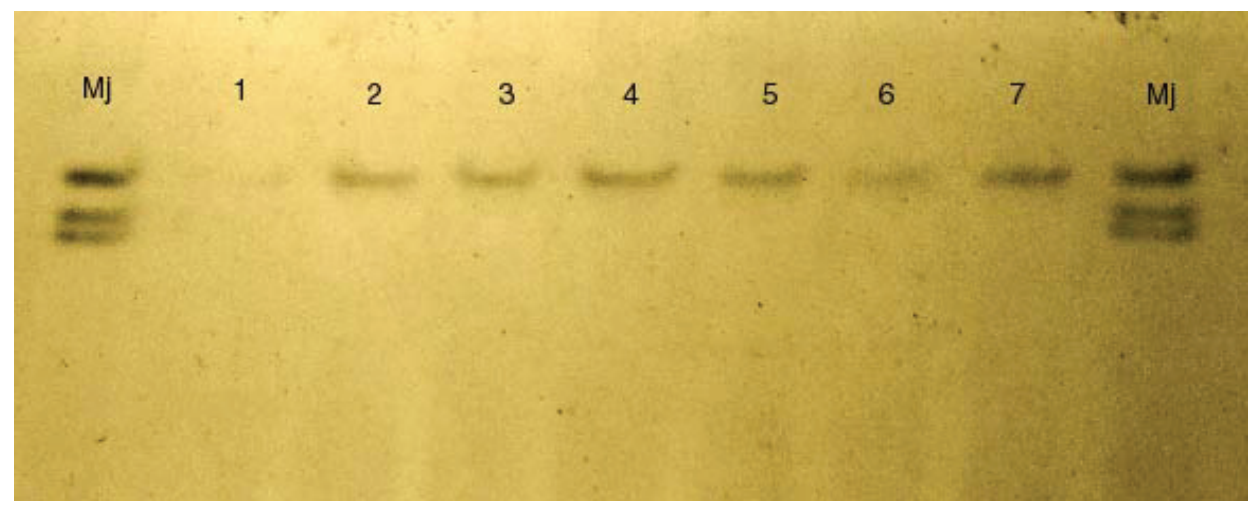

Figura 4. Gel de poliacrilamida 6\% apresentando os fenótipos de esterase de de Meloidogyne javanica (Mj; utilizada como padrão) e M. incognita extraídas de Colocasia sp (linhas 1 a 4) e Polianthes tuberosa (linhas 5 a 7).

Figure 4. Polyacrylamide gel 6\% showing the esterase phenotypes of Meloidogyne javanica (Mj; standard) and M. incognita extracted from Colocasia sp. (lines 1 to 4) e Polianthes tuberosa (lines 5 to 7). 

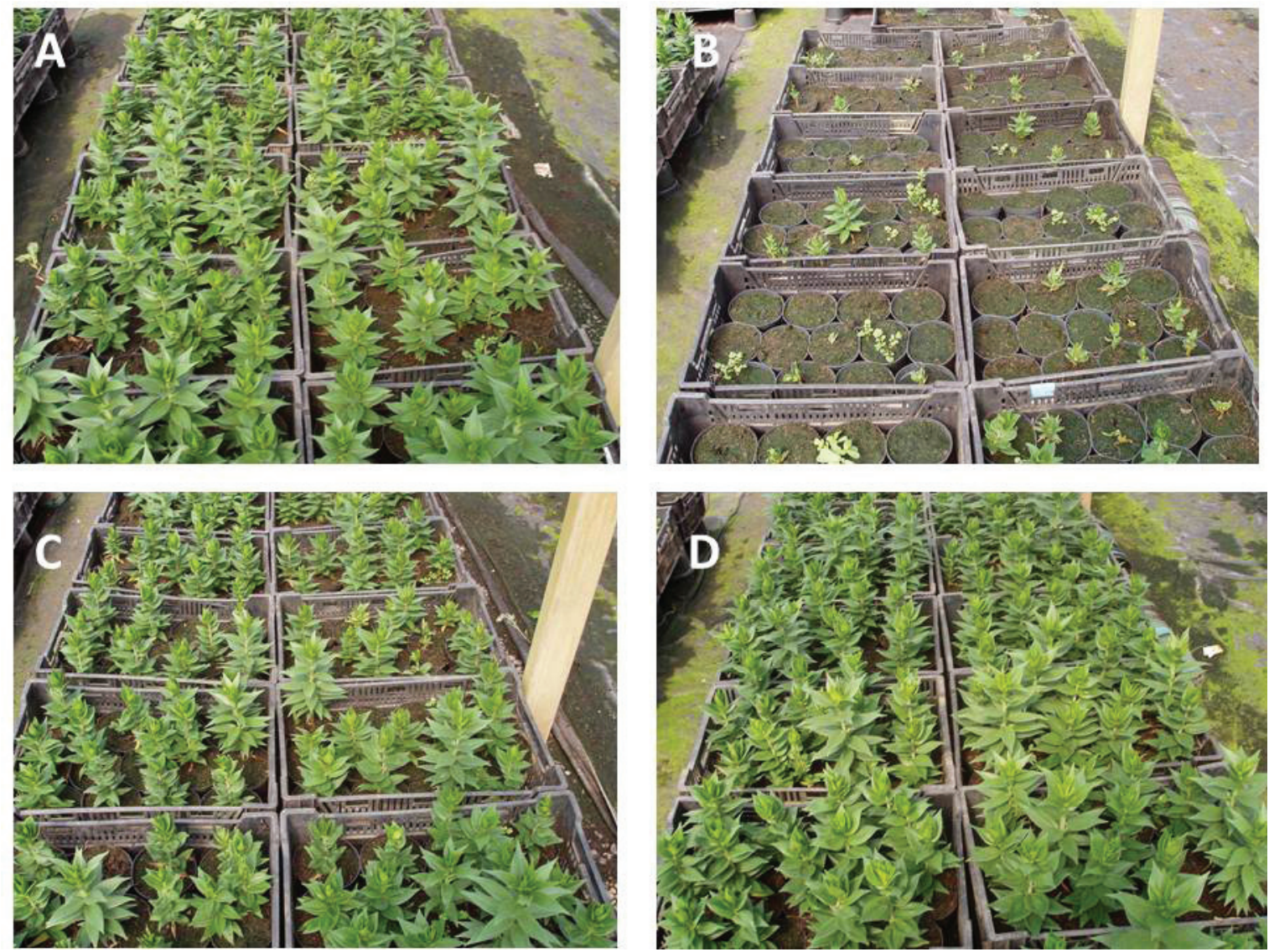

Figura 5. Efeito dos tratamentos hidrotérmicos na germinação dos bulbos de lírio. A - temperatura a $390 \mathrm{c} / 2 \mathrm{~h}$ sem formalina; B - temperatura a $42 \mathrm{oC} / 2 \mathrm{~h}$; C - temperatura a $39 \mathrm{oC} / 2 \mathrm{~h}$ com formalina $3 \%$; D - tratamento nematicida com Abamectina.

Figure 5. Effect of hidrotermotherapy on lily bulbs development. A - temperature at 39oC/2h without formalin; B - temperature at $42 \mathrm{oC} / 2 \mathrm{~h} ; \mathrm{C}$ - temperature at $39 \mathrm{oC} / 2 \mathrm{~h}$ with formalin $3 \%$; D - chemical treatment with Abamectina.

\section{Pratylenchus na raiz}

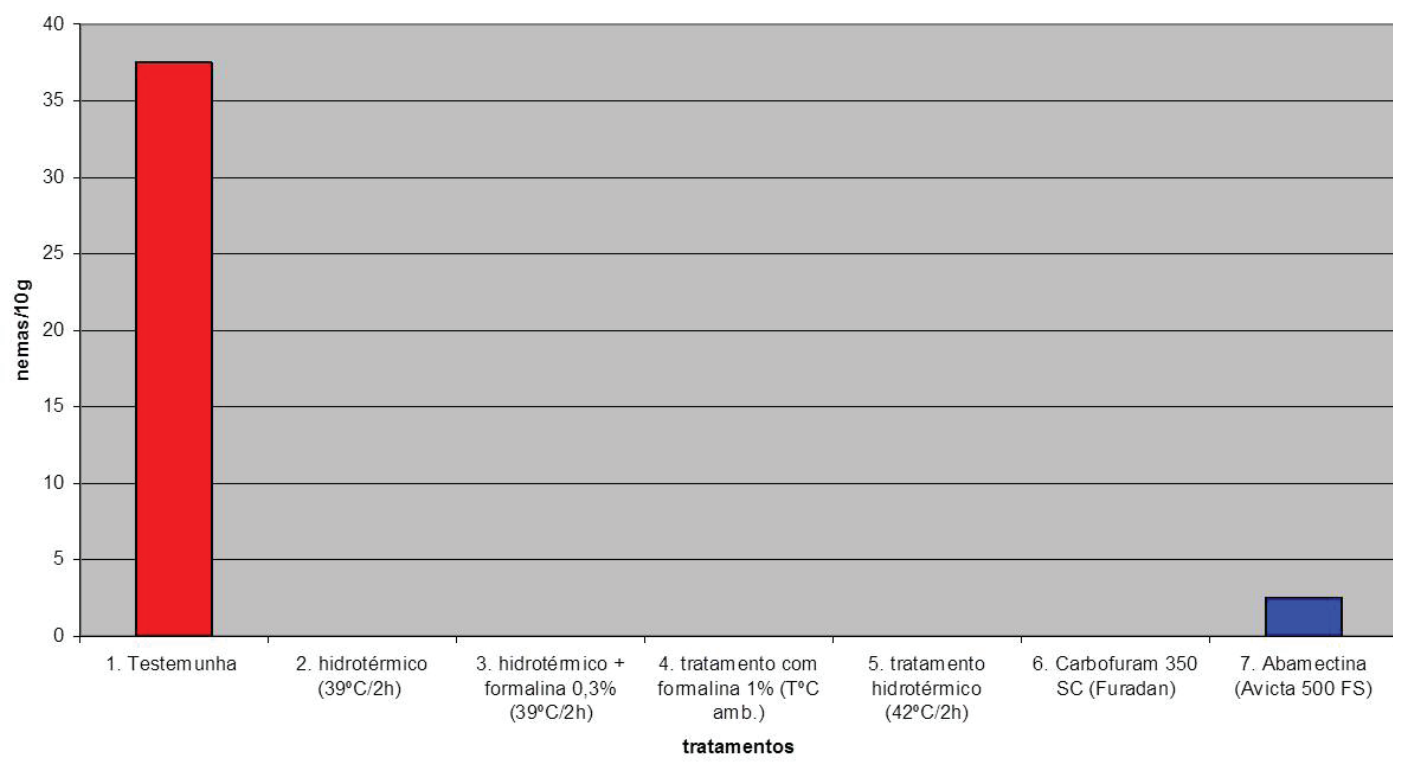

Figura 6. Número de espécimes de Pratylenchus crenatus presentes em 10g de raízes de lírio, 60 dias após os tratamentos.

Figure 6. Number of Pratylenchus crenatus present on $10 \mathrm{~g}$ of lily roots 60 days after treatments. 